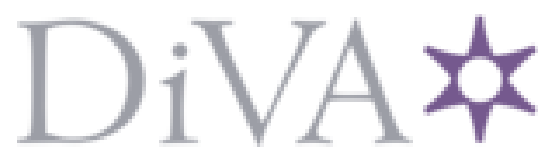

http://www.diva-portal.org

\title{
Postprint
}

This is the accepted version of a paper published in Clinical Biomechanics. This paper has been peerreviewed but does not include the final publisher proof-corrections or journal pagination.

Citation for the original published paper (version of record):

Dal Maso, F., Raison, M., Lundberg, A., Arndt, A., Allard, P. et al. (2015)

Glenohumeral translations during range-of-motion movements, activities of daily living, and sports activities in healthy participants..

Clinical Biomechanics, 30(9): 1002-1007

http://dx.doi.org/10.1016/j.clinbiomech.2015.06.016

Access to the published version may require subscription.

N.B. When citing this work, cite the original published paper.

Creative Commons Attribution Non-Commercial No Derivatives: CC BY-NC-ND

Permanent link to this version:

http://urn.kb.se/resolve?urn=urn:nbn:se:gih:diva-4131 


\section{Glenohumeral translations during range-of-motion movements, activities of daily living, and sports activities in healthy participants}

Authors:Fabien Dal Maso, Ph.D*; Maxime Raison, Ph.D; Arne Lundberg, MDPh.D; Anton Arndt, Ph.D; Paul Allard,Ph.D; Mickaël: Begon, Ph.D

\section{Addresses of the authors:}

Fabien Dal Maso, Paul Allard, and Mickaël Begon

Laboratoire de Simulation et de Modélisation du Mouvement; Département de kinésiologie, Université de Montréal, Montréal, Canada

Maxime Raison

Polytechnique Montréal, Montréal, Canada

Arne Lundberg

Karolinska Institutet, Stockholm, Sweden

Anton Arndt

The Swedish School of Sport and Health Sciences, Stockholm, Sweden; Affiliation: Karolinska Institutet, Stockholm, Sweden

\section{${ }^{*}$ Corresponding author:}

Fabien Dal Maso

Université de Montréal

1700 , rue Jacques Tétreault

Laval, QC, H7N 0B6, Canada

+15143436111-44017

fabien.dalmaso@gmail.com 


\section{Abstract}

Background: Glenohumeral translations have been mainly investigated during static poses while shoulder rehabilitation exercises, activities of daily living, and sports activities are dynamic. Our objective was to assess glenohumeral translations during shoulder rehabilitation exercises, activities of daily living, and sports activities to provide a preliminary analysis of glenohumeral arthrokinematics in a broad range of dynamic tasks.

Methods: Glenohumeral translations were computed from trajectories of markers fitted to intracortical pins inserted into the scapula and the humerus. Two participants (P1 and P2) performed full range-of-motion movements including maximum arm elevations and internal-external rotations rehabilitation exercises, six activities of daily living, and five sports activities.

Findings: During range-of-motion movements, maximum upward translation was $7.5 \mathrm{~mm}$ (P1) and $4.7 \mathrm{~mm}$ (P2). Upward translation during elevations was smaller with the arm internally ( $3.6 \mathrm{~mm}$ (P1) and $2.9 \mathrm{~mm}$ (P2)) than neutrally $(4.2 \mathrm{~mm}$ (P1) and $3.7 \mathrm{~mm}$ (P2)) and externally rotated $(4.3 \mathrm{~mm}$ (P1) and $4.3 \mathrm{~mm}$ (P2)). For activities of daily living and sports activities, only anterior translation during reach axilla for P1 and upward translation during ball throwing for P2 were larger than the translation measured during range-ofmotion movements (108\% and $114 \%$, respectively). 
Interpretation: While previous electromyography-based studies recommended external rotation during arm elevation to minimize upward translation, measures of glenohumeral translations suggest that internal rotation may be better. Similar amplitude of translation during ROM movement and sports activities suggests that large excursions of the humeral head may not be only caused by fast movements, but also by large amplitude movements.

Keywords: glenohumeral arthrokinematics; dynamic tasks; intracortical pins; CT-scan; reference values. 


\section{Introduction}

Translations of the humeral head relative to the glenoid fossa are part of the normal arthrokinematics of the glenohumeral joint. Up to $2 \mathrm{~mm}$ excessive glenohumeral translations have been reported using radiographies during static poses at different angle of arm elevation in patients with rotator cuff tears (Deutsch et al., 1996; Yamaguchi et al., 2000). Shoulder pathology may be linked with abnormal glenohumeral translations, which cause pain and discomfort (Milgrom et al., 1995). However, information on reference values measured in healthy participants during dynamic tasks is limited to characterize pathological translations. Also, the knowledge of the normal glenohumeral translations in activities of daily living (ADL) and rehabilitation exercises may provide relevant information to help physiotherapists to better direct treatment programs.

Currently, studies on glenohumeral translations focused on series of static arm poses because of experimental constraints (Bryce et al., 2010; Graichen et al., 2005; Massimini et al., 2012; San Juan and Karduna, 2010; Sharkey and Marder, 1995). However, most of ADL and sports activities require dynamic arm movements, and some recent findings encourage early

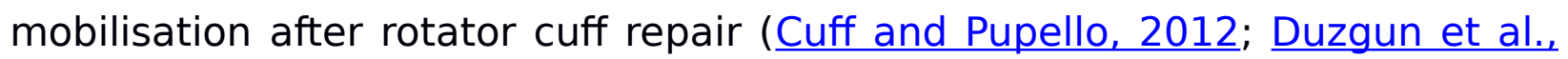
2011; Lee et al., 2012). Fluoroscopy-based experiments have been used to measure glenohumeral translations during dynamic tasks (Bey et al., 2008; Bishop et al., 2009; Giphart et al., 2013; Matsuki et al., 2012; Nishinaka et 
al., 2008) with an accuracy between $0.2 \mathrm{~mm}$ and $0.3 \mathrm{~mm}$ (Giphart et al., 2012). However, the radiation imposed by fluoroscopy limits the acquisition for each participant to about 30-s annually (Bey et al., 2008). Consequently, only dynamic arm flexion, scaption, abduction, and external rotation (Bey et al., 2008; Bishop et al., 2009; Giphart et al., 2013; Matsuki et al., 2012; Nishinaka et al., 2008) have been assessed to date, which represents a small fraction of the shoulder range-of-motion (ROM) comparatively to the total shoulder ROM (Haering et al., 2014; Veeger and van der Helm, 2007). In 2014, a method based on intracortical pins has permitted the measurement of glenohumeral translations during dynamic tasks with less than $0.15 \mathrm{~mm}$ error for one hour (Dal Maso et al., 2014). Such a method is appropriate to conduct an in-depth analysis of glenohumeral arthrokinematics during rehabilitation movements as well as ADL and sports activities.

Based on electromyographic recordings, dynamic elevations with the arm externally rotated and arm internal-external rotation at different abduction angles were recommended for shoulder rehabilitation (Ellenbecker and Cools, 2010; Kelly et al., 1996; Reinold et al., 2004; Worrell et al., 1992). These exercises, by decreasing the ratio of deltoid to rotator cuff activation, could minimize upward translation (Blasier et al., 1997). Investigations that actually measured glenohumeral translations have shown that upward translation was smaller during scaption than during abduction when the arm is externally rotated (Giphart et al., 2013). However, to the best of our 
knowledge, no study assessed elevations with other axial rotation of the arm. Moreover, arm internal-external rotations were only assessed with the arm adducted (Bey et al., 2008). Consequently, the assessment of glenohumeral translation during arm elevation and internal-external rotation in different planes of elevation with several axial rotations and arm elevations, respectively is required.

Routine daily activities such as hair combing, hand reaching to opposite axilla, and eating require up to $30 \%$ to $60 \%$ of the maximum glenohumeral elevation angle (Lovern et al., 2010). Though upward translation increases with glenohumeral elevation angle (Dal Maso et al., 2014; Nishinaka et al., 2008), glenohumeral translations have never been reported during ADL. Concerning sports activities, greater glenohumeral translations were reported in the dominant side of baseball pitcher (Sethi et al., 2004) during manual laxity examination. However, actual shoulder kinematics during throwing motion has only been measured in cadavers (Mueller et al., 2014), which provides limited information since glenohumeral translations are sensitive to muscular activity pattern (Graichen et al., 2005; von EisenhartRothe et al., 2002). To the best of our knowledge, glenohumeral translations during other overhead and throwing sports activities have not been reported to date. Therefore, the investigation of the glenohumeral translations in healthy shoulders during ball throwing and tennis forehand and backhand 
(McCann and Bigliani, 1994) may help to provide reference values for the assessment of athletic shoulders.

The purpose of this study was to provide a first assessment of normal translations at the glenohumeral joint during full ROM movements, six ADL and five sports activities. Firstly, it was hypothesized that elevations with the arm in external rotation and arm internal-external rotation exercises would minimize upward translation compared to elevations with the arm in internal axial rotation. Secondly, ADL would produce glenohumeral translations smaller than ROM movements, while sports activities are expected to produce larger glenohumeral translations than ROM movements.

\section{Material and Methods}

\subsection{Participants}

The experiment was approved by the local ethics committees of the Montreal University (Canada) and the Karolinska Institute (Sweden). Two males volunteered after signing an informed consent form. Their age was 27 and 44 years; height was 1.65 and $1.77 \mathrm{~m}$, and mass was 57 and $82 \mathrm{~kg}$ (P1 and P2, respectively). Their left shoulder Disabilities of the Arm, Shoulder and Hand (Hudak et al., 1996) scores were lower than 10.5 indicating a normal ROM, no history of pain, injury, or shoulder dysfunction. 


\subsection{Instrumentation}

To accurately measure glenohumeral translations of a few millimeters in a large volume of acquisition, shoulder kinematics was based on the trajectories of markers fitted to pins inserted into the scapula and humerus. During arm elevations, this method permitted to measure glenohumeral translations and rotation with less than $0.15 \mathrm{~mm}$ and $0.2^{\circ}$ error, respectively (Dal Maso et al., 2014).

A two-hour local anesthesia (AstraZeneca, Södertälje, Sweden) was administrated by an experienced surgeon. Two stainless steel self-drilling cortical pins (Synthes, Bettlach, Switzerland) were inserted into first third of the scapular spine (1.6 $\mathrm{mm}$ in diameter), and into the humeral shaft below the medial deltoid attachment (2.5 $\mathrm{mm}$ in diameter). Clusters of four and five reflective markers, whose trajectories were collected at $300 \mathrm{~Hz}$ using 18 optoelectric VICON ${ }^{\mathrm{TM}}$ cameras (Oxford Metrics Ltd., Oxford, UK), were fitted to the scapular and humeral pins, respectively (Figure 1). The pin insertion sites were determined in order to avoid muscles, nerves and blood vessels. Their orientations were determined to avoid contact between the reflective markers and the head or the neck during the movements. At the end of the surgical operation, insertion sites were cleaned, sterilized and covered with a sterile dressing. The procedure of pins insertion was performed in an operating room, under normal and sterile surgery conditions. 

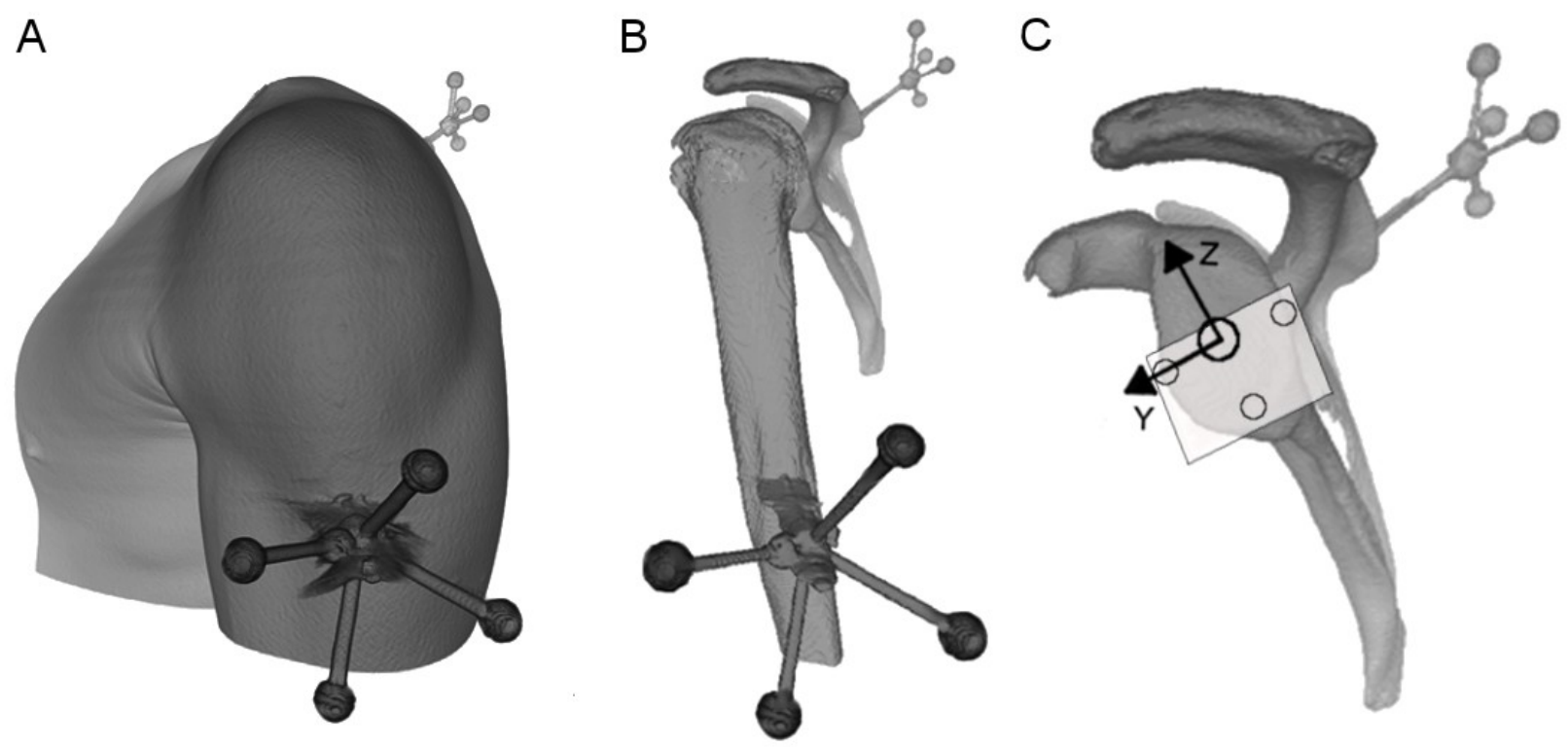

Figure 1: A) Representation of the CT-scan segmentation of a participant fitted with the intracortical pins inserted into the scapula and humerus and their respective clusters of markers. Volume rendering was adapted to visualize skin and markers. B) Representation of the CT-scan segmentation of the scapula and humerus bones with their respective clusters of markers. C) Representation of the CT-scan segmentation of the scapula and its cluster of markers. The plane represents the inferior glenoid plane (De Wilde et al., 2010) determined from the anterior, inferior, and posterior reference points indicated by circles on the glenoid rim. The $y$ - and z-axes represent the antero-posterior and longitudinal axes of the glenoid-based coordinate system. Positive values of antero-posterior and longitudinal translation indicated that the humeral head moved anterior and upward to the glenoid cavity, respectively. In B) and C), volume renderings were adapted to visualize bones. 
The 3D geometry of the bones with their respective pins and clusters of markers was obtained using a computed tomography scanner (CT-scan) (General Electric, Milwaukee, USA). X-ray tube current was adjusted at $120 \mathrm{kV}$ and $110 \mu \mathrm{A}$. The radiation dose was $1.5 \mathrm{mSv}$. The volume recorded corresponded to a rectangular parallelepiped of 226 slices of $0.61 \mathrm{~mm}$ of thickness spaced by $0.32 \mathrm{~mm}$. Each slice measured $250 \times 250 \mathrm{~mm}$ and was represented by a matrix of $512 \times 512$ pixels.

\subsection{Experimental procedures}

The participants were then taken to the biomechanics laboratory and were instructed to perform the following tasks. First, a relaxed trial and a series of movements including arm elevations, rotations, and circumductions (Jackson et al., 2012) were recorded to functionally locate the glenohumeral joint centre. Then, a total of 35 different dynamic tasks were collected. Each trial started with a relaxed position of the arm. Participants performed arm elevations and internal-external rotations to assess glenohumeral translations under their entire ROM (Haering et al., 2014). The elevations were performed with the elbow extended in four directions, namely, adduction (i.e. keep the arm as close to the trunk as possible throughout the movement), flexion, abduction, and extension. The arm was successively maintained in maximum internal, neutral, and maximum external rotation. During elevation with maximum internal and external rotation, from the 
relaxed position, participants rotated, and then elevated their arm as requested. Then internal-external axial rotations were performed with the elbow flexed and the arm elevated at 30,60 , and $90^{\circ}$ of thoracohumeral angle in the four abovementioned directions of elevation. Each movement was performed once. Finally, six trials of each ADL and sports activities were collected. ADL included reach front and back pocket, reach back, eating, hair combing, and reach the opposite axilla. Sports activities included tennis forehand and backhand with a tennis racket in the hand, throwing a ball, punching a bag and hockey shooting with a hockey stick in the hands.

At the end of the protocol, the participants were taken back to the operating room, and the surgeon removed the pins. The insertion sites were cleaned and covered with new sterile dressings. Antibiotic was prescribed to participants for one week (Heracillin, AstraZeneca, Sweden) and pain relief medication (Citodon, AstraZeneca, Sweden) was taken if desired. No clinical complications occurred after the experiment.

\subsection{Data processing}

An automatic segmentation of gray level of the CT-scan images was obtained using the Seg3D ${ }^{\circledR}$ software to identify all cluster-pin-bone voxels in each slice. The CT-scan slices were piled and bones 3D reconstructions containing up to 10,000 points were obtained for each bone using the iso2mesh Matlab ${ }^{\circledR}$ toolbox (Fang and Boas, 2009). Reference points located on the anterior, inferior, and posterior parts of the glenoid rim were used to determine the 
glenoid-based coordinated system (Figure 1C) (De Wilde et al., 2010). The reference points on the glenoid rim were identified five times by three evaluators; the inter-rater variability was $1.2 \mathrm{~mm}$.

A non-linear least-squares algorithm was applied to minimize the artefacts of raw markers trajectories (Monnet et al., 2012). The glenohumeral centre of rotation was located using the SCoRE algorithm (Ehrig et al., 2006). Then, glenohumeral kinematics was reconstructed with six degrees of freedom, namely, three translations and three rotations. Glenohumeral translations were calculated as the linear displacement of the glenohumeral centre of rotation in the glenoid-based coordinate system, the origin being its position during the relaxed trial (Massimini et al., 2012). Data were filtered using a $4^{\text {th }}$-order zero-lag Butterworth $10 \mathrm{~Hz}$ low-pass filter. Positive values of anteroposterior and longitudinal translations indicated that the humeral head was displaced anteriorly and upwardly relative to the glenoid cavity, respectively (Figure 1C).

\section{Results}

\subsection{Glenohumeral translations during full range-of-motion movements}

Table 1 presents the maximum glenohumeral translations measured during each movement in anterior, posterior, upward, and downward directions. Anterior translation reached up to $+3.4 \mathrm{~mm}(\mathrm{P} 1)$ and $+9.4 \mathrm{~mm}(\mathrm{P} 2)$. For P2, 
the largest anterior translation was measured in the first degrees of adduction and flexion with the arm in internal rotation (not presented). Besides these movements, maximum anterior translation did not exceeded $+4.4 \mathrm{~mm}$ for P2. Posterior translation reached up to $-3.2 \mathrm{~mm}$ (P1) and $-2.0 \mathrm{~mm}(\mathrm{P} 2)$. Upward translation reached up to $+7.5 \mathrm{~mm}(\mathrm{P} 1)$ and $+4.7 \mathrm{~mm}$ (P2). On average for $\mathrm{P} 1$, the largest upward translation was measured during all elevations in abduction $(7.0 \mathrm{~mm}$, average of the three axial rotations) and all elevations performed with the arm externally rotated $(4.3 \mathrm{~mm}$, average of the four directions of elevation). On average for $\mathrm{P} 2$, the largest upward translation was measured during all elevations with the arm externally rotated $(4.3 \mathrm{~mm}$, average of the four directions of elevation) and during all elevations in adduction $(4.2 \mathrm{~mm}$, average of the three axial rotations). Except in extension, elevations performed with the arm in internal rotation produced smaller upward translation $(3.6 \mathrm{~mm}(\mathrm{P} 1)$ and $2.9 \mathrm{~mm}(\mathrm{P} 2)$ ) than elevations with the arm in neutral $(4.2 \mathrm{~mm} \mathrm{(P1)} \mathrm{and} 3.7 \mathrm{~mm}$ (P2)) and external rotation $(4.3 \mathrm{~mm}(\mathrm{P} 1)$ and $4.3 \mathrm{~mm}$ (P2)). For both participants, upward translation was smaller during internal-external rotations (average: $2.7 \mathrm{~mm}(\mathrm{P} 1)$ and $2.0 \mathrm{~mm}(\mathrm{P} 2)$; range: $1.4-3.8 \mathrm{~mm}(\mathrm{P} 1)$ and $0.7-4.0 \mathrm{~mm}(\mathrm{P} 2))$ than during elevations (average: $4.1 \mathrm{~mm}(\mathrm{P} 1)$ and $3.6 \mathrm{~mm}$ (P2); range: 2.2$7.5 \mathrm{~mm}$ (P1) and 1.8-4.7 mm (P2)). Downward translation reached up to $-3.0 \mathrm{~mm}(\mathrm{P} 1)$ and $-2.7 \mathrm{~mm}(\mathrm{P} 2)$. 
Table 1: Maximum glenohumeral translations measured in all the directions during range-of-motion movements for both participants

\begin{tabular}{|c|c|c|c|c|c|c|c|c|c|c|}
\hline & \multirow[b]{2}{*}{$\begin{array}{l}\text { Directio } \\
\mathrm{n}\end{array}$} & \multirow[b]{2}{*}{$\begin{array}{l}\text { Arm } \\
\text { position }\end{array}$} & \multicolumn{4}{|l|}{ P1 } & \multicolumn{4}{|l|}{$\mathrm{P} 2$} \\
\hline & & & $\begin{array}{l}\text { Anteri } \\
\text { or }\end{array}$ & $\begin{array}{l}\text { Posteri } \\
\text { or }\end{array}$ & $\begin{array}{l}\text { Upwar } \\
\text { d }\end{array}$ & $\begin{array}{l}\text { Downwa } \\
\text { rd }\end{array}$ & $\begin{array}{l}\text { Anteri } \\
\text { or }\end{array}$ & $\begin{array}{l}\text { Posteri } \\
\text { or }\end{array}$ & $\begin{array}{l}\text { Upwar } \\
\text { d }\end{array}$ & $\begin{array}{l}\text { Downwa } \\
\text { rd }\end{array}$ \\
\hline \multirow{12}{*}{ Elevations } & \multirow{4}{*}{$\begin{array}{l}\text { Adducti } \\
\text { on }\end{array}$} & Internal & 2.5 & -0.6 & 2.6 & -0.9 & 9.4 & -1.3 & 3.9 & -2.1 \\
\hline & & Neutral & 2.5 & -0.7 & 2.6 & 0.2 & 3.4 & -1.6 & 4.6 & -1.4 \\
\hline & & External & 3.4 & -0.8 & 2.6 & -1.3 & 4.4 & -1.3 & 4.1 & -1.9 \\
\hline & & Internal & 2.5 & -3.2 & 2.2 & -3.0 & 6.3 & -2.0 & 2.9 & -2.4 \\
\hline & \multirow[t]{2}{*}{ Flexion } & Neutral & 1.0 & -1.7 & 4.1 & -0.7 & 1.8 & -1.5 & 4.7 & -1.2 \\
\hline & & External & 1.2 & -1.8 & 4.8 & -1.2 & 2.4 & -1.3 & 4.3 & -1.7 \\
\hline & \multirow{3}{*}{$\begin{array}{l}\text { Abducti } \\
\text { on }\end{array}$} & Internal & 1.8 & -0.8 & 6.2 & -1.2 & 1.9 & -1.1 & 1.8 & -0.9 \\
\hline & & Neutral & 2.0 & -0.5 & 7.5 & -0.8 & 2.6 & 0.0 & 2.9 & -0.7 \\
\hline & & External & 1.0 & -1.4 & 7.5 & -2.5 & 2.6 & -0.6 & 4.6 & -0.2 \\
\hline & \multirow{3}{*}{$\begin{array}{l}\text { Extensi } \\
\text { on }\end{array}$} & Internal & 1.6 & -1.6 & 3.4 & -1.4 & 3.7 & -1.6 & 2.9 & -1.9 \\
\hline & & Neutral & 1.2 & -0.9 & 2.7 & -1.5 & 2.1 & -0.5 & 2.5 & -1.5 \\
\hline & & External & 1.9 & -1.1 & 2.5 & -1.2 & n.a. & n.a. & n.a. & n.a. \\
\hline \multirow{12}{*}{$\begin{array}{l}\text { Internal- } \\
\text { external } \\
\text { rotations }\end{array}$} & \multirow{4}{*}{$\begin{array}{l}\text { Adducti } \\
\text { on }\end{array}$} & $30^{\circ}$ & 2.9 & -0.1 & 2.2 & -0.7 & 2.2 & -1.1 & 1.7 & -2.3 \\
\hline & & $60^{\circ}$ & 1.5 & -0.2 & 3.8 & 1.0 & 1.5 & -0.2 & 2.4 & 0.1 \\
\hline & & $90^{\circ}$ & 1.4 & -0.4 & 2.8 & 1.9 & 2.2 & -1.6 & 4.0 & -0.9 \\
\hline & & $30^{\circ}$ & 1.2 & -1.0 & 2.1 & -1.1 & 1.2 & -0.6 & 0.7 & -0.4 \\
\hline & \multirow[t]{2}{*}{ Flexion } & $60^{\circ}$ & 0.8 & -0.9 & 2.8 & 0.6 & 2.2 & 0.4 & 2.7 & -0.1 \\
\hline & & $90^{\circ}$ & 0.6 & -1.2 & 2.4 & 0.7 & 2.0 & -1.3 & 2.0 & 0.6 \\
\hline & \multirow{3}{*}{$\begin{array}{l}\text { Abducti } \\
\text { on }\end{array}$} & $30^{\circ}$ & 1.1 & -0.6 & 1.4 & 0.5 & 1.3 & -1.8 & 2.1 & -1.0 \\
\hline & & $60^{\circ}$ & 1.5 & -0.8 & 2.7 & -0.2 & 2.5 & 1.0 & 1.5 & -0.8 \\
\hline & & $90^{\circ}$ & 2.6 & 0.1 & 3.2 & 1.5 & n.a. & n.a. & n.a. & n.a. \\
\hline & \multirow{3}{*}{$\begin{array}{l}\text { Extensi } \\
\text { on }\end{array}$} & $30^{\circ}$ & 1.3 & -0.1 & 3.0 & -0.9 & 4.3 & 1.1 & 0.7 & -2.7 \\
\hline & & $60^{\circ}$ & 2.6 & -1.2 & 3.7 & -2.2 & n.a. & n.a. & n.a. & n.a. \\
\hline & & $90^{\circ}$ & n.a. & n.a. & n.a. & n.a. & n.a. & n.a. & n.a. & n.a. \\
\hline
\end{tabular}




\subsection{Glenohumeral translations during activities of daily living and sports activities}

During ADL, the linear velocity of the hand ranged between $0.5 \mathrm{~m} \cdot \mathrm{s}^{-1}$ and $2.0 \mathrm{~m} . \mathrm{s}^{-1}(\mathrm{P} 1)$ and $0.9 \mathrm{~m} . \mathrm{s}^{-1}$ to $2.5 \mathrm{~m} . \mathrm{s}^{-1}(\mathrm{P} 2)$. Table 2 presents the maximum glenohumeral translations measured in all directions during ADL and sports activities. During ADL, anterior translation reached up to $3.7 \mathrm{~mm}$ for $\mathrm{P} 1$ (reach axilla) and $6.2 \mathrm{~mm}$ for $\mathrm{P} 2$ (reach back). The anterior translation for P1 when reaching axilla was $108 \%$ larger than the maximum anterior translation measured during ROM movements. Upward translation reached up to $4.8 \mathrm{~mm}$ and $4.3 \mathrm{~mm}$ when combing hair for P1 and P2, respectively. Reaching back produced large downward translation for P1 $(-2.3 \mathrm{~mm})$ and P2 (-5.1 $\mathrm{mm})$.

During sports activities, the linear velocity of the hand ranged between 15.9 and $41.0 \mathrm{~m} . \mathrm{s}^{-1}(\mathrm{P} 1)$ and 11.0 and $30.0 \mathrm{~m} \cdot \mathrm{s}^{-1}(\mathrm{P} 2)$. Anterior translation reached up to $3.0 \mathrm{~mm}$ for P1 (punching) and $4.7 \mathrm{~mm}$ for P2 (hockey shooting). Hockey shooting and ball throwing were the sports activities that produced the largest upward translation for both participants $(5.0 \mathrm{~mm}$ and $3.6 \mathrm{~mm}$ for $\mathrm{P} 1$, and $4.3 \mathrm{~mm}$ and $5.4 \mathrm{~mm}$ for $\mathrm{P} 2$, respectively). Upward translation when throwing a ball for P2 was $114 \%$ larger than the maximum upward translation measured during ROM movements. Overall, the excursion of the humeral head in the anterior and upward directions was in the same range during ADL, sports activities, and ROM movements (Figure 2). 
Table 2: Maximum translations measured in all the directions during activities of daily living and sports activities for both participants

\begin{tabular}{|c|c|c|c|c|c|c|c|c|c|}
\hline & & \multicolumn{4}{|l|}{ P1 } & \multicolumn{4}{|l|}{$\mathrm{P} 2$} \\
\hline & & $\begin{array}{l}\text { Anterio } \\
\mathrm{r}\end{array}$ & $\begin{array}{l}\text { Posterio } \\
\mathrm{r}\end{array}$ & $\begin{array}{l}\text { Upwar } \\
\text { d }\end{array}$ & $\begin{array}{l}\text { Downwar } \\
\text { d }\end{array}$ & $\begin{array}{l}\text { Anterio } \\
\mathrm{r}\end{array}$ & $\begin{array}{l}\text { Posterio } \\
\mathrm{r}\end{array}$ & $\begin{array}{l}\text { Upwar } \\
\text { d }\end{array}$ & $\begin{array}{l}\text { Downwar } \\
\text { d }\end{array}$ \\
\hline \multirow{6}{*}{$\begin{array}{l}\text { Activities of } \\
\text { daily living }\end{array}$} & $\begin{array}{ll}\text { Reach front } \\
\text { pocket }\end{array}$ & 2.1 & -0.3 & 2.1 & -0.4 & 2.7 & -0.2 & 2.3 & -0.9 \\
\hline & $\begin{array}{l}\text { Reach } \text { back } \\
\text { pocket }\end{array}$ & 2.5 & -0.1 & 2.8 & -0.7 & 5.0 & 0.4 & 2.6 & -2.3 \\
\hline & Reach back & 1.5 & -0.6 & 2.4 & -2.3 & 6.2 & -0.4 & 2.3 & -5.1 \\
\hline & Hair combing & 1.8 & -1.1 & 4.8 & -0.5 & 2.2 & -1.2 & 4.3 & -1.4 \\
\hline & Eat & 1.4 & -0.7 & 1.9 & -1.0 & 1.9 & -1.9 & 1.9 & -1.0 \\
\hline & Reach axilla & 3.7 & -0.7 & 1.3 & -1.3 & n.a. & n.a. & n.a. & n.a. \\
\hline \multirow{5}{*}{$\begin{array}{l}\text { Sports } \\
\text { activities }\end{array}$} & Tennis forehand & 2.5 & -0.3 & 2.8 & -0.6 & 2.5 & -0.3 & 2.8 & -0.6 \\
\hline & Tennis backhand & 2.3 & -0.1 & 2.3 & -0.7 & 2.3 & -0.1 & 2.3 & -0.7 \\
\hline & Ball throwing & 2.1 & -1.4 & 3.6 & -1.2 & 3.0 & -2.9 & 5.4 & -3.3 \\
\hline & Punching & 3.0 & -0.2 & 2.8 & -0.3 & n.a. & n.a. & n.a. & n.a. \\
\hline & Hockey shooting & 2.4 & -0.9 & 5.0 & -0.8 & 4.7 & -0.1 & 4.3 & -0.5 \\
\hline
\end{tabular}



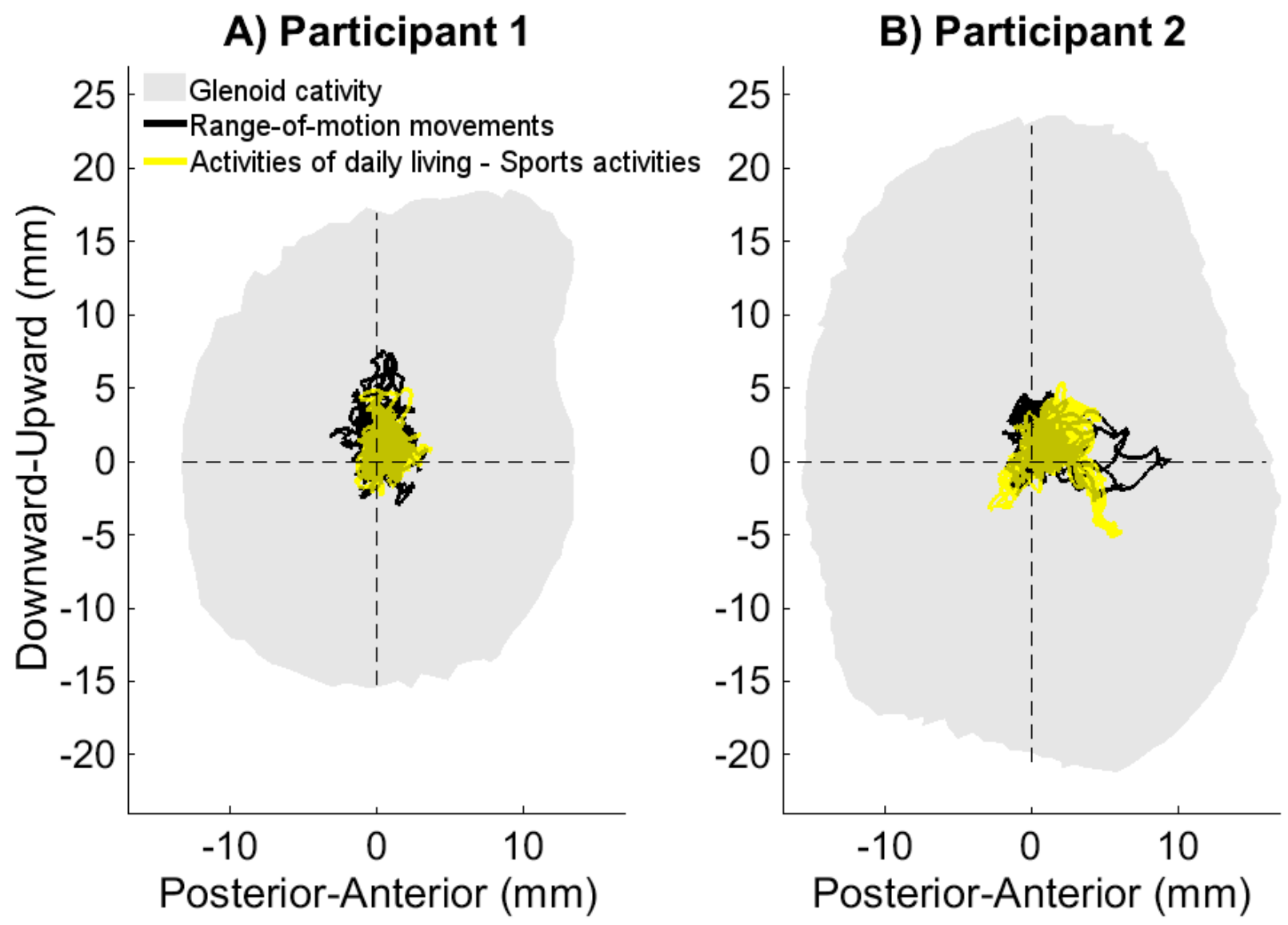

Figure 2: Projection of the position of the humeral head centre on the glenoid cavity (light gray) during ROM movements (black) and activities of daily living and sports activities (yellow) in P1 (A) and P2 (B).

\section{Discussion}

This study assessed for the first time glenohumeral translations during 35 different dynamic tasks including full ROM movements, ADL, and sports activities. The main findings are firstly that upward translations were minimized (i) when the arm was maintained in internal rotation during 
elevations and (ii) during all arm internal-external rotations. Secondly, ball throwing was the only sport activity that produced larger upward translation than ROM movements only for one participant.

\subsection{Limitations}

Since the technique used to measure glenohumeral translations is invasive, a small sample was assessed. In effect, radiation imposed by CT-scan corresponded to the annual radiation exposure from natural sources and pins were screwed into the bones. The present limitation is a common limitation for studies using intracortical pins. Indeed, previous sample varied between one (Ryu et al., 2009) and eight (McClure et al., 2001) participants. The exception is the cohort of P. Ludewig (University of Minnesota) with 24 participants (Lawrence et al., 2014). The proposed method, however, enables to measure glenohumeral translations with four advantages, namely, accuracy of about $0.15 \mathrm{~mm}$ (Dal Maso et al., 2014), large volume acquisition, sampling rate of $300 \mathrm{~Hz}$, and long anesthesia duration to acquire 35 different dynamic tasks. By comparison, the accuracy of fluoroscopy ranged between $0.2 \mathrm{~mm}$ and $0.3 \mathrm{~mm}$ (Giphart et al., 2012), and the acquisition was limited to

a dozen movements (Bey et al., 2008). Moreover, capture volume and sampling rate are inappropriate for sports activities. Therefore, results based on two participants may contribute as a benchmark for large scale studies. 


\subsection{Glenohumeral translations during full range-of-motion movements}

Contrary to our hypothesis, elevations with the arm in external rotation did not reduce but increased upward translation comparatively to elevations with the arm held in internal rotation. The ratio of deltoid to rotator cuff activation has been shown to decrease with the arm externally rotated during elevations, and was assumed to minimize upward translation (Ellenbecker and Cools, 2010; Reinold et al., 2007). However, the conversion of electromyographic signal into force is a non-linear process (Buchanan et al., 2004; Lloyd and Besier, 2003; Winby et al., 2013). Though more active during elevation with arm external rotation, rotator cuff muscles may generate insufficient downward shear forces to counteract the upward shear forces generated by deltoid muscles and minimize upward translation. Moreover, other factors such as capsule (Ishihara et al., 2014) and ligaments (Moorman et al., 2012) are known to limit glenohumeral translations. Consequently, only electromyography-based results may not be sufficient to provide recommendations for shoulder rehabilitation. Since shoulder rehabilitation is a complex multi-factorial process (Ellenbecker and Cools, 2010), our results suggest that a comprehensive evaluation of shoulder girdle biomechanics including glenohumeral translations is required to better direct rehabilitation programs. The initial position of the humeral head was not provided in the present study. As evidenced by Henseler et al. (2014), the latter may be considered in further studies since combination of initial 
position of the humeral head and glenohumeral translations information can be an indicator of rotator cuff tears. The measure of the distance between the acromion and the humerus may also provide clinically relevant input of the space allocated to the rotator cuff tendons.

Regarding our findings, extensions, all elevations with the arm in internal rotation, as well as arm internal-external rotation exercises minimized upward translation in healthy participants. Further large scale investigations focusing on shoulder rehabilitation may target in priority these movements, especially if the number of trial acquired is limited such as with biplane fluoroscopy.

\subsection{Glenohumeral translations during activities of daily living and sports activities}

During dynamic arm elevations, upward translation and elevation angle are linearly and positively correlated (Dal Maso et al., 2014). In the present study, which included also ADL and sports activities, the ADL requiring large arm elevation angle (i.e. hair combing), produced also the largest upward translation for both participants. Large upward translation may consistently occur at high arm elevation angle and contribute to the high prevalence of rotator cuff injuries observed in overhead workers (Harkness et al., 2003; Koester et al., 2005).Also, our observations emphasize that shoulder kinematics may differ between static and dynamic tasks since maximum upward translation was reported at low arm elevation angles during static 
poses (Graichen et al., 2005; Graichen et al., 2000; Massimini et al., 2012). As stated previously (Massimini et al., 2012), the systematic assessment of glenohumeral translations during dynamic tasks is essential to better characterize shoulder kinematics.

Ball throwing was the only sport activity that produced larger translation than ROM movements in the upward direction for one participant. During tennis forehand, tennis backhand, and punching, the amplitude of glenohumeral translations did not exceeded maximum glenohumeral translations measured during ROM movements. These results suggest that large excursions of the humeral head are not only caused by fast movements, but also by movements of large amplitude. The limited glenohumeral translations measured in non-athlete participants during sports activities may be due to active contribution of glenohumeral stabilizer muscles (Blache et al., 2015; Escamilla et al., 2009) and intact passive structures (Mihata et al., 2015). This may suggest that the assessment of expert athletes would only provide relevant information to understand the mechanisms underlying excessive translations during manual laxity testing (Lintner et al., 1996; Sethi et al., 2004). Interestingly, hockey shooting produced large upward translation for both participants although this task did not require high arm elevation angle. Other factors such as closed-loop movement, may also influence upward glenohumeral translation. 
In conclusion, our in-vivo dynamic measurements of glenohumeral arthrokinematics provided reference values of translations during full rangeof-motion movements, activities of daily living and sports activities in healthy participants. During elevations upward translation was smaller when the arm was in internal rotation than in neutral and external rotation. This result suggests that large scale studies relying on a comprehensive analysis of shoulder girdle biomechanics including glenohumeral translations are necessary to make recommendations for shoulder rehabilitation exercises. Glenohumeral translations during six activities of daily living and five sports activities were in the same range as those during full range-of-motion movements, which suggests that large excursion of the humeral head is caused by both fast and large movements.

\section{Acknowledgements}

We thank the RRSSTQ that supported this work. In addition, the MEDITIS training program in biomedical technologies (NSERC, CREATE program) supported the postdoctoral fellowship of the first author. None of these programs played a role in the present investigation. We thank also Talia Alenabi for her advices regarding shoulder pathologies. 


\section{References}

Bey, M.J., Kline, S.K., Zauel, R., Lock, T.R., Kolowich, P.A., 2008. Measuring dynamic in-vivo glenohumeral joint kinematics: technique and preliminary results. J Biomech 41, 711-714.

Bishop, J.L., Kline, S.K., Aalderink, K.J., Zauel, R., Bey, M.J., 2009. Glenoid inclination: in vivo measures in rotator cuff tear patients and associations with superior glenohumeral joint translation. J Shoulder Elbow Surg 18, 231236.

Blache, Y., Dal Maso, F., Desmoulins, L., Plamondon, A., Begon, M., 2015. Superficial shoulder muscle co-activations during lifting tasks: Influence of lifting height, weight and phase. Journal of Electromyogr Kines 25, 355-362.

Blasier, R.B., Soslowsky, L.J., Malicky, D.M., Palmer, M.L., 1997. Posterior glenohumeral subluxation: active and passive stabilization in a biomechanical model. J Bone Joint Surg Am 79, 433-440.

Bryce, C.D., Davison, A.C., Okita, N., Lewis, G.S., Sharkey, N.A., Armstrong, A.D., 2010. A biomechanical study of posterior glenoid bone loss and humeral head translation. J Shoulder Elbow Surg 19, 994-1002. 
Buchanan, T.S., Lloyd, D.G., Manal, K., Besier, T.F., 2004. Neuromusculoskeletal modeling: estimation of muscle forces and joint moments and movements from measurements of neural command. J Appl Biomech 20, 367-395.

Cuff, D.J., Pupello, D.R., 2012. Prospective randomized study of arthroscopic rotator cuff repair using an early versus delayed postoperative physical therapy protocol. J Shoulder Elbow Surg 21, 1450-1455.

Dal Maso, F., Raison, M., Lundberg, A., Arndt, A., Begon, M., 2014. Coupling between 3D displacements and rotations at the glenohumeral joint during dynamic tasks in healthy participants. Clin Biomech 29, 1048-1055.

De Wilde, L.F., Verstraeten, T., Speeckaert, W., Karelse, A., 2010. Reliability of the glenoid plane. J Shoulder Elbow Surg 19, 414-422.

Deutsch, A., Altchek, D.W., Schwartz, E., Otis, J.C., Warren, R.F., 1996. Radiologic measurement of superior displacement of the humeral head in the impingement syndrome. J Shoulder Elbow Surg 5, 186-193.

Duzgun, I., Baltaci, G., Atay, O.A., 2011. Comparison of slow and accelerated rehabilitation protocol after arthroscopic rotator cuff repair: pain and functional activity. Acta orthopaedica et traumatologica turcica 45, 23-33. 
Ehrig, R.M., Taylor, W.R., Duda, G.N., Heller, M.O., 2006. A survey of formal methods for determining the centre of rotation of ball joints. J Biomech 39, 2798-2809.

Ellenbecker, T.S., Cools, A., 2010. Rehabilitation of shoulder impingement syndrome and rotator cuff injuries: an evidence-based review. $\mathrm{Br}$ J Sports Med 44, 319-327.

Escamilla, R.F., Yamashiro K Fau - Paulos, L., Paulos L Fau - Andrews, J.R., Andrews, J.R., 2009. Shoulder muscle activity and function in common shoulder rehabilitation exercises. Sports Med 39, 663-685.

Fang, Q., Boas, D.A., 2009. Tetrahedral mesh generation from volumetric binary and grayscale images, Biomedical Imaging: From Nano to Macro, 2009. ISBI '09. IEEE International Symposium, pp. 1142-1145.

Giphart, J.E., Brunkhorst, J.P., Horn, N.H., Shelburne, K.B., Torry, M.R., Millett, P.J., 2013. Effect of Plane of Arm Elevation on Glenohumeral Kinematics: A Normative Biplane Fluoroscopy Study. J Bone Joint Surg 95, 238-245.

Giphart, J.E., van der Meijden, O.A., Millett, P.J., 2012. The effects of arm elevation on the 3-dimensional acromiohumeral distance: a biplane fluoroscopy study with normative data. J Shoulder Elb Surg 21, 1593-1600. 
Graichen, H., Hinterwimmer, S., von Eisenhart-Rothe, R., Vogl, T., Englmeier, K.H., Eckstein, F., 2005. Effect of abducting and adducting muscle activity on glenohumeral translation, scapular kinematics and subacromial space width in vivo. J Biomech 38, 755-760.

Graichen, H., Stammberger, T., Bonel, H., Karl-Hans, E., Reiser, M., Eckstein, F., 2000. Glenohumeral translation during active and passive elevation of the shoulder - a 3D open-MRI study. J Biomech 33, 609-613.

Haering, D., Raison, M., Begon, M., 2014. Measurement and Description of Three-Dimensional Shoulder Range of Motion With Degrees of Freedom Interactions. Journal of Biomechanical Engineering 136, 084502-084502.

Harkness, E.F., Macfarlane, G.J., Nahit, E.S., Silman, A.J., McBeth, J., 2003. Mechanical and psychosocial factors predict new onset shoulder pain: a prospective cohort study of newly employed workers. Occupational and environmental medicine 60, 850-857.

Henseler, J.F., de Witte, P.B., de Groot, J.H., van Zwet, E.W., Nelissen, R.G.H.H., Nagels, J., 2014. Cranial translation of the humeral head on radiographs in rotator cuff tear patients: the modified active abduction view. Medical \& Biological Engineering \& Computing 52, 233-240. 
Hudak, P.L., Amadio, P.C., Bombardier, C., 1996. Development of an upper extremity outcome measure: the DASH (disabilities of the arm, shoulder and hand). The Upper Extremity Collaborative Group (UECG). Am J Ind Med 29, 602-608.

Ishihara, Y., Mihata, T., Tamboli, M., Nguyen, L., Park, K.J., McGarry, M.H., Takai, S., Lee, T.Q., 2014. Role of the superior shoulder capsule in passive stability of the glenohumeral joint. J Shoulder Elbow Surg 23, 642-648.

Jackson, M., Michaud, B., Tetreault, P., Begon, M., 2012. Improvements in measuring shoulder joint kinematics. J Biomech 45, 2180-2183.

Kelly, B.T., Kadrmas, W.R., Speer, K.P., 1996. The manual muscle examination for rotator cuff strength. An electromyographic investigation. Am J Sports Med 24, 581-588.

Koester, M.C., George, M.S., Kuhn, J.E., 2005. Shoulder impingement syndrome. Am J Med 118, 452-455.

Lawrence, R.L., Braman, J.P., Laprade, R.F., Ludewig, P.M., 2014. Comparison of 3-dimensional shoulder complex kinematics in individuals with and without shoulder pain, part 1: sternoclavicular, acromioclavicular, and scapulothoracic joints. J Orthop Sports Phys Ther 44, 636-645, A631-638. 
Lee, B.G., Cho, N.S., Rhee, Y.G., 2012. Effect of Two Rehabilitation Protocols on Range of Motion and Healing Rates After Arthroscopic Rotator Cuff Repair: Aggressive Versus Limited Early Passive Exercises. Arthroscopy: The Journal of Arthroscopic \& Related Surgery 28, 34-42.

Lintner, S.A., Levy, A., Kenter, K., Speer, K.P., 1996. Glenohumeral translation in the asymptomatic athlete's shoulder and its relationship to other clinically measurable anthropometric variables. Am J Sports Med 24, 716-720.

Lloyd, D.G., Besier, T.F., 2003. An EMG-driven musculoskeletal model to estimate muscle forces and knee joint moments in vivo. J Biomec 36, 765776.

Lovern, B., Stroud, L.A., Ferran, N.A., Evans, S.L., Evans, R.O., Holt, C.A., 2010. Motion analysis of the glenohumeral joint during activities of daily living. Comput Methods Biomech Biomed Engin 13, 803-809.

Massimini, D.F., Boyer, P.J., Papannagari, R., Gill, T.J., Warner, J.P., Li, G., 2012. In-vivo glenohumeral translation and ligament elongation during abduction and abduction with internal and external rotation. J Orthop Surg Res 7, 29.

Matsuki, K., Matsuki, K.O., Yamaguchi, S., Ochiai, N., Sasho, T., Sugaya, H., Toyone, T., Wada, Y., Takahashi, K., Banks, S.A., 2012. Dynamic in vivo 
glenohumeral kinematics during scapular plane abduction in healthy shoulders. J Orthop Sports Phys Ther 42, 96-104.

McCann, P.D., Bigliani, L.U., 1994. Shoulder pain in tennis players. Sports Med $17,53-64$.

McClure, P.W., Michener, L.A., Sennett, B.J., Karduna, A.R., 2001. Direct 3dimensional measurement of scapular kinematics during dynamic movements in vivo. J Shoulder Elb Surg 10, 269-277.

Mihata, T., McGarry, M.H., Ishihara, Y., Bui, C.N.H., Alavekios, D., Neo, M., Lee, T.Q., 2015. Biomechanical Analysis of Articular-Sided Partial-Thickness Rotator Cuff Tear and Repair. Am J Sports Med 43, 439-446.

Milgrom, C., Schaffler, M., Gilbert, S., van Holsbeeck, M., 1995. Rotator-cuff changes in asymptomatic adults. The effect of age, hand dominance and gender. The Journal of bone and joint surgery. British volume 77, 296-298.

Monnet, T., Thouze, A., Pain, M.T., Begon, M., 2012. Assessment of reproducibility of thigh marker ranking during walking and landing tasks. Med Eng Phys 34, 1200-1208.

Moorman, C.T., Warren, R.F., Deng, X.H., Wickiewicz, T.L., Torzilli, P.A., 2012. Role of coracoacromial ligament and related structures in glenohumeral 
stability: a cadaveric study. Journal of surgical orthopaedic advances 21,210 217.

Mueller, A.M., Rosso, C., Entezari, V., McKenzie, B., Hasebroock, A., Cereatti, A., Della Croce, U., Nazarian, A., Ramappa, A.J., DeAngelis, J.P., 2014. The effect of supraspinatus tears on glenohumeral translations in passive pitching motion. Am J Sports Med 42, 2455-2462.

Nishinaka, N., Tsutsui, H., Mihara, K., Suzuki, K., Makiuchi, D., Kon, Y., Wright, T.W., Moser, M.W., Gamada, K., Sugimoto, H., Banks, S.A., 2008. Determination of in vivo glenohumeral translation using fluoroscopy and shape-matching techniques. Journal of Shoulder and Elbow Surgery 17, 319322.

Reinold, M.M., Macrina, L.C., Wilk, K.E., Fleisig, G.S., Dun, S., Barrentine, S.W., Ellerbusch, M.T., Andrews, J.R., 2007. Electromyographic analysis of the supraspinatus and deltoid muscles during 3 common rehabilitation exercises. J Athl Train 42, 464-469.

Reinold, M.M., Wilk, K.E., Fleisig, G.S., Zheng, N., Barrentine, S.W., Chmielewski, T., Cody, R.C., Jameson, G.G., Andrews, J.R., 2004. Electromyographic analysis of the rotator cuff and deltoid musculature during 
common shoulder external rotation exercises. J Orthop Sports Phys Ther 34, 385-394.

Ryu, T., Soon Choi, H., Chung, M.K., 2009. Soft tissue artifact compensation using displacement dependency between anatomical landmarks and skin markers - a preliminary study. International Journal of Industrial Ergonomics 39, 152-158.

San Juan, J.G., Karduna, A.R., 2010. Measuring humeral head translation using fluoroscopy: a validation study. J Biomech 43, 771-774.

Sethi, P.M., Tibone, J.E., Lee, T.Q., 2004. Quantitative assessment of glenohumeral translation in baseball players: a comparison of pitchers versus nonpitching athletes. Am J Sports Med 32, 1711-1715.

Sharkey, N.A., Marder, R.A., 1995. The rotator cuff opposes superior translation of the humeral head. Am J Sports Med 23, 270-275.

Veeger, H.E., van der Helm, F.C., 2007. Shoulder function: the perfect compromise between mobility and stability. J Biomech 40, 2119-2129.

von Eisenhart-Rothe, R.M., Jager, A., Englmeier, K.H., Vogl, T.J., Graichen, H., 2002. Relevance of arm position and muscle activity on three-dimensional 
glenohumeral translation in patients with traumatic and atraumatic shoulder instability. Am J Sports Med 30, 514-522.

Winby, C.R., Gerus, P., Kirk, T.B., Lloyd, D.G., 2013. Correlation between EMGbased co-activation measures and medial and lateral compartment loads of the knee during gait. Clinical biomechanics (Bristol, Avon) 28, 1014-1019.

Worrell, T.W., Corey, B.J., York, S.L., Santiestaban, J., 1992. An analysis of supraspinatus EMG activity and shoulder isometric force development. Med Sci Sports Exerc 24, 744-748.

Yamaguchi, K., Sher, J.S., Andersen, W.K., Garretson, R., Uribe, J.W., Hechtman, K., Neviaser, R.J., 2000. Glenohumeral motion in patients with rotator cuff tears: a comparison of asymptomatic and symptomatic shoulders. J Shoulder Elbow Surg 9, 6-11. 